\title{
CHILDLESSNESS AND WOMEN MANAGERS: 'CHOICE', CONTEXT AND DISCOURSES
}

\begin{abstract}
Childlessness is increasing and might reflect acceptance of diversity, scope for individual choice, and a creative 'social imaginary' about being feminine without being a mother. Childlessness also appears to have a contextual manifestation arising from the recognition that the long hours work culture in many organizations does not support appropriate parenting. A qualitative study of Australian managers reveals the contradictory discourses of childlessness around enlightened equality, maternalism, an elusive, ideal 'work-life balance', and individualism. The paper explores a contextually nuanced, dynamic, generative theory of agency, which does not hinge on the mother-child dyad, in explaining women managers' choices to remain childless.
\end{abstract}

Keywords: Gender, Childlessness, Women, Managers 
Despite a growing number of women in management (Parker and Fagenson, 1994), large surveys of women and men in management inevitably come up with very gendered patterns of marital status and childlessness (Still, 1993; Wajcman, 1999). Although the popular press is also reporting the same phenomenon on a wider scale in the general population (e.g. Manne, 2002; Shanahan, 2002), the proportion of women in management without children is quite striking.

In US research, Brett and Stroh (1999, p.392) sampled 1000 US managers and found $45 \%$ of females were married, compared with $86 \%$ of males, with $62 \%$ of the men having children at home, while only $20 \%$ of the women did so. Other studies from the US report similar findings, suggesting childlessness among women in management is now double that among male counterparts. For example, Hewlett (2002) reports that 59\% of female managers are childless, compared to $29 \%$ of male managers.

In Britain, similar trends are observed (Wajcman, 1999; see also Davidson and Cooper 1992). Indeed, according to Wajcman (1999, p.143), 'childlessness is a precondition of a successful management career'. Her British study showed strong gender differences in marital status and childlessness. Twenty seven percent of the women, compared with $7 \%$ of the men in her study were single, divorced or separated. Two thirds of the women did not have children. In a 1991 study of Australian female managers, Still (1993) reported a profile of $55 \%$ as single or divorced. As in the British research, two thirds of the sample $(n=253)$ had no children.

Scholarly literature on childlessness has tended to bifurcate along materialist and post-structural feminist lines. Materialist, liberal feminist or equal opportunity approaches tend to position childlessness as a loss of human rights due to discriminatory practices and policies and/or a biological biproduct of infertility and delayed efforts to reproduce. Post-structural approaches make more of the positive agency of women in challenging pronatalist agendas for women in society that see developmental psychology, social norms and psychoanalytical cultural feminism denying women without children an adult, sanctioned status. In making such challenges, women pioneer new ways of being feminine (Hird and Abshoff, 2000; Morell, 1993; Rowland 1982a; Rowland 1982b).

The very term 'childlessness' posits a loss and absence of something deemed important, but in the absence of clear indicators that this state is a result of conscious, deliberate choice, we have used this term in preference to 'childfree'. The term childlessness is used to indicate an end state that is a result of infertility and/or social contexts. There are a number of competing discourses of childlessness. The paper will analyze current theorizing on attitudes to childlessness to understand how dominant discourses help shape women's understandings and choices about childlessness. Analysis of interview data from research on Australian managers reveals competing and contradictory discourses surrounding childlessness. Family-friendly workplaces and work-life balance discourses and practices have done little to 
reverse the growing trend of childlessness amongst women managers and provide the context for considering the notion of the choice to be childless.

The paper argues that we need a more critical and nuanced understanding of the context and subjective experiences of women managers who 'choose', as much as choice can be assumed, to be childless. It also suggests, along with McNay (2000), that we need a theoretical base that does not hinge on psychoanalytical aspects of mother and child to explain gendered behaviour in contemporary work settings.

\section{Demographic trends in childlessness}

Most women continue to become mothers at some time of their life but since the post World War Two boom in fertility, there has been an increasing trend towards childlessness among western women. In the UK twice as many women in 1991 expected to remain childless than those in 1986. In 1991 the Office of Population Census and Surveys forecast that $20 \%$ of women cohorts born in the 60s, 70s and 80s would remain childless (Gillespie, 2000, p.223). Bachu (cited in Park, 2002) focused on women aged 40 to 44 and found that between 1980 and 1998 childlessness doubled from 10\% to 19\% (Park, 2002, p.27). Heaton, Jacobson and Holland (1999) project that for women born in 1952, 22\% will remain childless.

This dramatic increase is also reported in Australia. Australian Bureau of Statistics (ABS) data claims that more Australian women will be childless than either US or British women. Estimates for 2000 suggest that $24 \%$ of women currently in their reproductive years will never have children, compared with $22 \%$ in the US and $20 \%$ in the UK (ABS, 2002, p.37). Demographic data reveal a broad correlation between childlessness and higher average ages of mothers at the birth of the first child. According to the ABS, '[V]oluntary childlessness of a temporary nature may become involuntary in circumstances where women delay having children to a point where they are no longer able to conceive or carry a pregnancy to full term' (ABS, 2002, p.38).

In the US, the higher the education level of a woman, the more likely such postponing will take place (Heaton, et al., 1999, p.537). Though some respondents in a study by Heaton et al. (1999) made an early and permanent decision to be childless, others simply postponed having children until age, career, education, established lifestyle, and related factors significantly reduced the possibility of having children (Heaton, et al., 1999, p.539). Therefore, there is the possibility that a large group of those postponing child bearing, may leave it too late.

There are also gaps between stated intentions and ultimate outcomes in childlessness. Although we have seen an increase in childlessness, most US teenage women expect to have children in the future (Thornton and Young-De Marco, 2001, p.13/25). In the US, Abma (cited in Park, 2002) claimed in 1997 that $8.9 \%$ of their female sample (aged 15-44) were, or expected to remain, childless, $6.6 \%$ of those voluntarily. A recent qualitative study of slightly older 
Australians aged 22-30, however, found that while almost all of the males desired to partner permanently and to have children, only 'over half' of the females did so (White, 2003). Early childbearing intentions are not necessarily borne out and may alter over the life course. Decisions take place 'within the context of changing life events and relationships' (Hird and Abshoft, 2000, p.354).

Three main factors, then, can be isolated from the demographic data: voluntary childlessness (being childfree) is increasing, but childlessness is still a minority position. Secondly, the intention to have children is higher, generally, in teenage years than ultimate outcomes quantify. Thirdly, decisions about reproducing are contextual.

The characteristics of the childless give us more insight into the phenomenon. In the US the demographic characteristics of childlessness are similar for men and women, in income, education, age and desire for leisure time and social activities (Heaton et al., 1999). Professional women such as doctors and lawyers are reported to have a high rate of childlessness (Hewlett, 2002). In addition, the childless 'tend to be well-educated, live in urban areas, have little or no religious affiliation, and hold non-traditional sex roles', according to Somers, (1993, p.643). The Australian childless women similarly have high participation in the workforce, are more likely to work full time and the proportion increases with level of education (20\% have a Bachelor degree or higher) (ABS 2002, p.39). The married are also more likely to have children (Heaton et al., 1999; Monk, Essex, Smider, Klein, Lowe and Kupfer, 1996; Somers, 1993).

Therefore, workforce participation, education level, marital and residential status may each be important correlates of childlessness. Demographic change understandably has seen parallel change, or at least contestation of mainstream, normative values about motherhood and parenthood, and these issues are explored in the following literature.

\section{Theorizing attitudes to childlessness}

Choice has been a central and contested concept in the social sciences and in the lived experience of what Giddens (1990) calls the conditions of late modernity (Hughes, 2002). It is linked to the notion of agency, and connotes notions of freedom in the West (Lopez, 2001, p.88; Varela, 2001, p.88). As we have seen, feminist accounts have taken divergent paths of micro, post structural analyses prioritizing agency and symbolic understandings (Pringle, 1988; Whatmore, Marsden and Lowe, 1994; Cosslett, Easton and Summerfield, 1996) as well as a general materialist, equal opportunity and deterministic accounts of structural inequality (Burton, 1991; Hewlett, 2002; Summers, 2003). Hughes believes post-structural feminism bridges the opposition between agency and structure by allowing for a doubled sense of subject: 'subject/ed to and subject of action', neither fully free nor fully determined (Hughes, 2002, p.99). McNay's work on agency strengthens this bridge and takes up the challenge of Hird and Abshoft (2000) to develop theory that does not recreate a maternal essence. 
In her book, Gender and Agency, Lois McNay, attempts to theorize the durability of gender identity, the disappointing lack of emancipation, and the possible bias towards accounts of resistance and subversion. Frameworks derived from Foucault and Lacan create, according to McNay, a reactive model of agency centred on the mother-child dyad: a 'tacitly maternal model of agency' (2000, p.11) that encourages us to view women's agency as a reaction in the form of subversion, rebellion and so forth. The focus on the symbolic has not always allowed us to appreciate how symbolic dimensions are refracted through material dimensions of power (2000, p.14). Current tensions in women's identities are likely to have arisen from the nonmothering aspects of women's roles.

McNay suggests that careful use of Bourdieu's concept of 'field' allows us to move beyond dualisms of home/work, public/private and so on through a view of social structure that incorporates refractory elements in a historical matrix. The field embodies a complicated logic that more ably reflects 'the experience and uncertainty of women's social experience' (2000, p.27). Furthermore, use of Casoriadis' concept of the 'social imaginary' allows us to view agency as a creative, generative act rather than as a maternally modelled reaction to a 'lack', or response to a dissonance between the psyche and society.

McNay's exposition is valuable because it allows an accommodation of feminist scholarship that appears to have been travelling along divergent paths. In this case ideas about being childless or childfree can be clearly seen in a historical context of conflicting pressures. Gender identities 'are not free floating: they involve deep-rooted investment on the part of individuals and historically sedimented practices which severely limit their transferability and transformability' (2000, p.18).

For some time it has been recognised that childless women deviate in some way from essentialist notions of woman as mother (Gillespie, 2000; Hird and Abshoff, 2000; Letherby and Williams, 1999; Park, 2002). The voluntarily childless woman, in particular, perceives negative evaluations by others, although scholars have found higher marital cohesion and satisfaction among childless couples than parents (Monk, et al., 1996, p.1238; Somers, 1993, p.647).

Relatively small sampled qualitative studies from the United States and Britain argue that the deviance of childlessness may provoke strategies whereby women 'manage' a stigmatized identity or construct alternative views of the good, feminine woman. For example, Park (2002, p.32-37) demonstrates how the voluntarily childless, in a pro-natalist US environment, use strategies such as giving the impression they may be infertile, or that they may have children in the future, and recasting the meaning of selfishness and 'contribution to society'. Morell (1993), on the other hand, argues that some poorer US women challenge and resist gender expectations to be mothers from early ages and have 'compelling desires for self-expression, for independence, for an education, and for economic self-sufficiency' (Morell, 1993, p.2/7). Hird and Abshoff (2000) also highlight the positive decision to be child-free made by 
more women in recent times and resist the assumption that a childless outcome should be represented as a negative loss.

Alexander, Rubinstein, Goodman and Luborsky (1992) agree that attitudes to childlessness change through the life course, most of their 90 older informants reporting their regret intensifying in older age (p.620). They were, however, able to think about their life critically and to offer resistance to normative pronatalist judgments about their 'wasted' lives.

In a British study, Gillespie (2000, p.231) also reveals resistance to the dominant motherhood discourse and a determination to construct a feminine identity separate from motherhood (although the role of 'child-substitute' pets is hinted for some). The childless women are met with disbelief and negative stereotypes of being 'hard' and 'unfeminine' when they reveal their intentions. These women strongly rejected assumptions that childlessness represented failed or flawed femininity. For example, they claimed that beautiful underwear, nice clothes, painted nails and a better figure (from not being a mother) could make them more feminine in some ways. The ultimate feminine woman thus forgoes the bodily risks of motherhood and focuses on the personal consumption of products required for sexual attractiveness.

Ambivalence both in attitudes to childlessness and the decision to remain childless is another theme. Other people respond to the childless with pity derived from an 'unquestioning belief in the positive experience of motherhood' and envy from 'those who felt negatively about motherhood and its constraining effects on women's lives' (Letherby and Williams, 1999, p.723). The so-called decision to be childless or 'childfree' was also ambivalent as, even when women did experience making a clear decision (not to have children), the stories they told to account for that decision were complex and inconclusive, open to shifts, revelation, and reconstruction. Rather than a choice, remaining childless was described as an ongoing practice and/or an outcome determined by a variety of personal or social circumstances (Morrell, cited by Letherby and Williams, 1999, p.724. See also Hird and Abshoff, 2000, p.354).

Letherby and Williams (1999, p.727) argue that complexity in attitudes to non motherhood underlines the important aspect that all women do not share the same realities, and that there is recognition of another way of living life without children (see also Becker and Moen, 1999, p.8/13). Some recognition of minority positions or diversity of lifestyles is also indicated by larger studies.

Thornton and Young-DeMarco (2001), in a broad ranging quantitative North American study about trends in attitudes to family issues between the 1960s and 1990s, noted that there was a ' substantial and persistent long term trend towards tolerance. . . towards diversity. . .' (2001, pp.1-25) that included more tolerance for childlessness. Support for the notion that a couple ought to have children decreased from $85 \%$ approval in 1962, to $40 \%$ in the 1980 s, and through to the 1990s. The idea that people without children lead empty lives had $45 \%$ disagreeing in 1988, but by 1994 more than half $(56 \%)$ of those women surveyed in the International Social Science Project disagreed with 
this concept. The minority view that parenthood was restrictive increased during the time frame and, interestingly, became more of an issue for male respondents than for female respondents from the late 1980s to mid 1990s. Commitment to marriage, family and children coexists with commitment to 'equality, tolerance and freedom' so deciding to be childless is likely to continue as a real choice for US residents, according to Thornton and YoungDeMarco (2001, pp.16-25). Such change has occurred in the face of opposition from the religious right or fundamentalist Christianity (Kesler, 1999), a factor less likely to have an impact in Australia.

Thornton and Young-De Marco's North American study also found trends towards 'individual autonomy' and 'gender equality' although commitment to the latter seemed to be greater among women than among men. Interestingly, within this widespread acceptance of gender equality, there was also a strong current of continued support of a gendered domestic division of labour (Thornton and Young-De Marco, 2001, pp.15-25), which has also been discussed in relation to the phenomenon of childlessness, specifically among women in management.

\section{Family work nexus}

The discourses of marital and work equality (not mirrored in positivist behavioural research) have failed to supplant or eradicate a discourse on gendered child rearing and domestic work which is mirrored in statistical norms and household data (Becker and Moen, 1999; Burton, 1991; Davidson and Cooper, 1992; Parker and Fagenson, 1994; Pringle and Tudhope, 1996; Stratton, 2003; White, 2003, p.158). Wacjman (1999, p.133) has noted that sociological studies bridging family and work have been limited due to different academic traditions. Policy wise, however, the two areas have been united with family friendly work initiatives.

Many workers recognise the conflicts between what may be called two 'greedy institutions' that of family and work (Franzway, 2000), and governments unions and businesses have attempted to introduce familyfriendly policies on economically rationalist grounds of a more productive workforce, as much as concern for the future of the family (AAP, 2002; Adie and Carmodie 1991, p.4; Casey, 1995, pp.121-2; Family Friendly Work Practices, 1999; Family Friendly Work Rules, 2002; Gray and Tudball, 2002, pp.34-35; Lee 2001; Meyerson and Fletcher, 2000; Walterscheid, 1993; Wolcott and Glezer, 1995; Zacharias, 2002, p.26). Such policies have not had the intended impact.

Recent surveys in Australia support the idea of a longer work hours culture, two thirds of men and almost a quarter of women working more than 41 hours a week and a little less than half working over eight hours unpaid overtime a week. For higher status workers this is intensified (Glezer and Wolcott, 1999, p.70; Sexton, 2002, p.5). The long hours culture and the fear that an acknowledged need for help caring for a sick dependent or flexible leave might affect career advancement, has worked against effective take up and realization of benefits from family friendly policies in Australia, the US and 
Britain (Gray and Tudball 2002, p.1; Harker, 1995, p.104; Liff and Ward, 2001; Prince, 1998, pp.1-2; Quinn, 2001; Zacharias 2002; Zetlin and Whitehouse, 1998, cf. Jenner 1994). Thomson (1998) argues that the ultimate capitalist market society is 'childless'. Backlash political action by the childfree in relation to workplace discrimination might reinforce this opinion (Jenner, 1994; see also Zetlin and Whitehouse, 1998, p.11).

An Australian study provides valuable insight on the family work nexus, in relation to managers in particular. Wajcman and Martin (2002, p.995; p.998) highlight that while male and female Australian managers are remarkably similar in the 'market narrative' of their career experiences and their attitudes, women's private narratives reveal a 'deep sense of conflict' or 'stark choice' in resolving conflicting claims, compared with men. They argue that '[P]rivate identities remain . . . integrally and fundamentally gendered' and are 'the increasingly dominant source of the quite different "family-work" choices and dilemmas men and women face' (Wajcman and Martin, 2002, p.1000). A starting point of many social understandings, often unacknowledged, is the lived reality that women are seen as those with the most loyalty and commitment to the family institution. This contrasts with ideal notions of marital and parental equality that Dempsey (2002) and Gilding (1997) have noted are not always borne out in practice and thus involve cognitive dissonance for many women. Childlessness and Management

In Britain being 'a successful senior manager currently requires an over-riding commitment to work and as Wajcman says, the job consumes most waking hours and dominates life in every respect' (Wajcman 1999, p.156). Wajcman's (1999) study of British managers provides a clearly etched picture of a gendered family work nexus. Her questionnaire sample from five multinational companies in oil, chemicals and computing was made up of 108 female and 216 male senior managers, matched across as many variables as possible. A qualitative sample with twenty typical men and women managers from one case study was also used. Only $27 \%$ of the partnered men in the study had partners working full-time compared with $88 \%$ of similar women (p.140), and male managers did half the housework that female managers did (p.144). Wajcman concluded that 'while many women sacrifice their employment opportunities in order to have children, the women in my study have mostly given up the opportunity to have children in order to pursue their careers.' (1999, p.156). She also argues that the 'sacrifice of a family life is in vain' as most do not achieve the expected career advancement (Wajcman, 1999, p.143).

Although much is made of equality in contemporary marriage arrangements, domestic responsibilities in the British study reveal inequality. The 'domestic arrangements necessary and sufficient to sustain the life of a senior manager are very different for men and women' (Wajcman, 1999, p.132). Therefore, it would appear that a management career is still largely dependent on 'services of the wife at home'.

Liff and Ward (2001) extend our understanding of the centrality of gender to the managerial family-work nexus, opting for a theoretical framework that does not overestimate the agency of women. They argue that the scarcity of 
women in senior management (2\% in banks) is not a result of their lack of interest in such positions. In Liff and Ward's UK study, research interviews with 52 managers were conducted to explore male and female junior management's assessment of the senior positions. Junior managers believed that motherhood would 'spell the end of their career' , in spite of organizations expressing their commitment to equality and family friendly policies (Liff and Ward, 2001, p.26). This response was not surprising given the very small number of visible senior women with children.

Senior managers revealed that the most important downside to their status was conflicts between work and family, but men experienced it differently to women. 'For men it was regret that they could not see more of their children. For women it was exhaustion from trying to maintain two roles' (Liff and Ward, 2001, p.24).

Women more than men considered active parenting as a factor that would affect their career decisions. The study found that information about how work could be moulded to family needs was not readily available and 'there was a strong feeling that the organization was not willing in practice to support, or adapt to, parents and were likely to interpret any interest in, say, reduced hours as a lack of commitment to career' (Liff and Ward, 2001, p.26). The long hours culture was believed to be a greater indicator of commitment than quality of work.

Some women acted on these beliefs. Although a third of the women had children, only one had taken a career break and three had had a period of working part time. The majority had taken maternity leave but one had her second child during her holiday period. The strong perception that promotion was based on creating the right impression informally, operated differently for women than men. Women expected or wanted to play a significant role in their children's upbringing and were aware of stereotypes of women leaving to have babies. Anecdotal comments and informal interactions in which promotion was seen 'as synonymous with childlessness' acted as a countervailing force to family and equal opportunity policies (Liff and Ward, 2001, p.27; p. 34). Liff and Ward argue that women's responses in this context appear to be seen as a rejection of the way management is currently organized and an avoidance of certain aspects of a masculine organizational culture.

The meanings of families and children have changed through time, and it is not so long ago that children were valued more for economic survival and transmission of property rather than for the psycho-social reasons of sentiment prioritised in more modern times (Hird and Abshoff, 2000, p.349). The high incidence of contemporary childlessness should be viewed in terms of the current economic, political and religious contexts, which have given women the opportunity to define themselves in terms other than motherhood, a decision reached over time. Up until recently, though, scholars have pathologized such women and failed to appreciate the positive aspects of the reasons given of which freedom, career, education and an enhanced marital relationship appear most significant (Hird and Abshoff, 2000, pp.351-5). Of perhaps most import is the failure of feminist approaches to really challenge motherhood, and in fact their tendency to valorize women's procreative 
potential and mothering practices. Reproduction has been presented as an essential basis to shared subjectivity of women. Hird and Abshoff challenge feminist scholars to construct a theory of womanhood independent of motherhood and to reconsider the viability of arguments based 'in essence' on women's material relation to sexual reproduction. Childlessness is now central to experiences of womanhood and femininity (2000, pp. 355-61).

\section{Background to the Australian study}

The research reported in this paper arose a recent large survey (Wood and Lindorff, 2001, Wood 2001; 2003) on the attitudes to promotion by male and female Australian middle managers drawn from all twelve industry divisions in the Australian industry classifications (ABS, 1996). The study extended the debate on perceptual differences, and found that men and women perceived differently factors influencing their past and future promotion prospects, although similarities were noted on many dimensions.

The majority of the female sample $(n=156)$ were under 35 years of age $(56 \%$ cf $25 \%$ males), and were of Anglo-Saxon descent. One respondent was of Chinese origin. Both males and females had very similar educational qualifications, with $52 \%$ of females (cf $50 \%$ males, $n=351$ ) holding a University qualification. More female managers held undergraduate degrees in related areas of management, such as Business/Management, Accounting and Economics degrees (31\%) compared to their male counterparts (22\%). In addition, 3\% of female managers held an MBA post-graduate qualification, compared to $4 \%$ of male managers. All respondents were classified as middle managers as they had junior managers reporting to them, and they themselves reported to senior levels of management. The majority of the sample strongly indicated a desire to achieve a further senior promotion in their career (83\% male, $76 \%$ female managers).

Results of this study highlighted a strikingly gendered pattern of marital status and childlessness, including the finding that only $14 \%$ of female managers had dependent pre-school children. Significantly fewer female managers were in couple relationships (66\%, cf male managers $89 \%)$, and significantly fewer had dependent children (21\%, cf male managers 66\%). Thirty five per cent of male managers (who were somewhat older) had pre-school children, compared to $14 \%$ of female managers. The high proportion of young women in the sample goes some way to explaining the low numbers of women who had children. The vast majority of the female managers in the background study were under 40 years of age ( $71 \%$ compared with $29 \%$ of males). This represents 110 women out of 155 under the age of 40 . This figure is higher than that reported by Still (1993) in her 1991 study where two thirds of her sample was under 40 years of age.

In spite of the general predominance of females in the under forty age bracket, in this sample a dramatic change occurred in the 35-39 years age group, where male managers became predominant (24\% compared to $14 \%$ of females). One reason for this could be that from 35 years of age, the percentage of women managers decline because this age corresponds with what is commonly perceived to be the last 5 years or so to have a child. 
However, this is older than the average age in Australia considered as 'prime child bearing ages', which is 25-34 year group (Australian Women's Year Book, 1997, p.71). This suggests that women working in management roles may put off having children until after they have established themselves in a career, and then perhaps return to work. At an age when women are believed to re-enter the workforce after children enter school, however, (e.g. 35-44 years of age, see Australian Women's Year Book, 1997, p.71), the number of women in middle management positions in the sample did not revert to where they were previously. In fact, the numbers of women in management over 35 did not equal those of males in any subsequent age group. This background study pursued some issues in relation to childlessness but was not its main focus. The Interviews: competing discourses

The interview study that developed out of this background research was able to explore more deeply the issue of childlessness. It attempted to address some of Hird and Abshoff's concerns in relation to choice and childlessness in that it aims to avoid the essentializing and pathologizing tendencies of earlier feminist theories around maternity and childlessness.

Qualitative interviews were carried out with 10 male and 10 female managers, representing 10 organizations and Table 1 describes their demographic characteristics.

\section{(Table 1 here)}

Several questions probing the attitudes of female managers were utilized in a semi-structured interview. The letters and numbers in brackets after quotations refer to the sex and rank of the respondent, age, living arrangements and whether they have pre-school dependent children or not as shown in Table 2.

\section{(Table 2 here)}

The following analysis is set out around the three specific questions asked in the interview concerning: (i) the combination of career and marriage/family; (ii) responsibility for dependent children; and (iii) explanations for the high rate of childlessness among female managers. Four main discourses emerged : an enlightened discourse of equality, a discourse of elusive balance, a maternalistic discourse, and a discourse of individual choice. These overlap between men and women and within individuals, so can be seen to compete within individuals as well as between them.

\section{Combining Career with Marriage and Family}

In order to elicit perceptions relating to a career and family commitments, female middle managers of single and couple status, and a range of ages were asked: "What are your views on women combining marriage or a family and a career?" The majority of female respondents (7/10) drew on an 'enlightened' discourse around the positive value of women combining career and marriage, and respect for women who managed to achieve both. This discourse coincided with a less clearly articulated frame, crystallizing in the concept of 'balance' and embodying notions of an 'elusive ideal' or 'impossible dream'. For example: I admire people who do it, to balance career and personal life ( $F M,<30, ' O$ ', 0$)$, and I have a huge amount of admiration for 
those who can achieve it; I think organizations have made some inroads into that area. Women should be able to maintain a balance in life (FM, 30-35, Single, 0$)$, and It is to be applauded! (FM, 50-55, C, 0).

Furthermore, some older female managers (3/10) broadened th e area of contention by noting that it was problematic to combine marriage and a career. Personally, I have always combined marriage with a career. In retrospect, I don't think it is a very good idea. I have missed a lot of time with my children who have now grown up. Where have all those years gone? Maybe there is more to life than having a career and the financial aspects. What is important maybe is being close to the family. My family are not close to me now (FM, 50-55, S, 0).

Another respondent expressed ambivalence about combining career and babies and hinted at a maternalistic discourse prioritizing childrearing: I have mixed views, especially where infants are involved. If a woman has to work she misses out a lot. Maybe they should just try it out for a while to see if they can do it (FM, 40-44, S, 0).

Male middle managers' responses reflected an adherence to the 'enlightened' discourse, more clearly located as secondary to a primary adherence to maternalism or at least gendered marital obligations. For example: There is nothing wrong with combining marriage with a career as long as marriage has priority ( $M M, 50-55, C, 0)$. A discourse of individual agency appeared dominant in contrast to any engagement with structural factors and the significant, but elusive, goal of 'balance' was noted here, too, by a male. For example, It's difficult, but it very much depends on the individual, how they organize themselves, and what their motivation is. Some people appear to have a lot of trouble with it. It's a fine balance (MM, 40-44, S, 0).

These views suggest that although women and men in management invoked the 'enlightened' discourse which advocates equality of access to career and family, the women in particular also drew discursively on notions of an elusive ideal of 'balance', focusing more on the difficulties associated with career and children. These women, all without current dependent children, acknowledged the need for positive family relationships and expressed regret if this were to be sacrificed. Furthermore, the majority of women intimated that when women combined the roles of marriage and career a respectful appreciation, and even awe was attributed to these women who have achieved this. An older female manager who had experienced the 'enlightened' reality, expressed regret for the loss of family closeness. In this instance, a fine difference in perception can be discerned, and some commonality in recognition that a woman is, and perhaps should be, the person with major responsibility for family and domestic work. Such a maternalistic discursive angle was even more strongly reflected among the male managers.

Responsibilities for Dependent Children

A second question was then posed: "What are your views on who should be responsible for dependent children"? Three types of answers emerged. Those deemed responsible were 'mothers', 'both parents', and 'the choice of the 
couple', alluding to an individual choice discourse. The most frequent response by female managers (9/10) was derivative of an enlightened discourse where both parents should be responsible for the children, female managers endorsing this view strongly. Sometimes, however they added modifiers which indicated the power of parallel, contradictory discourses and, in one case, some engagement with structural factors acting on the 'subject'. For example: l've never had dependent children. It should be a joint responsibility, but the burden falls to the mother (FM, 50-55, C, 0). Both. The woman often feels more responsible. Nowadays, if it is known women are taking their own sick leave for their children, it comes out of their annual leave ( $F M, 40-44, S, 0)$. This respondent recognises that in the case of her institution there was punishment for women caring for sick children.

Male middle manager responses indicated that a sharing of responsibility was the ideal, e.g. Both should be responsible (MM, 40-44, S, 0), and We share the responsibility ( $M M, 45-50, C, 0)$. However, once again, sometimes this ideal response was modified (in terms of the role of women in families). For example: Both parents are responsible for dependent children. But I still like to see mothers spend prime time with the children, particularly at a young age (MM, 50-55, C, 0).

These comments and those in response to the first question appear to be more complex than first impressions warrant. There are hidden clues from the female responses that those responding 'both' imply that it will mostly be mothers who are responsible. While acknowledging that the questions were phrased in terms of the female experience, it can still be discerned that the statements indicate a concurrence of discourses in tension or contradiction: a shift from the genderless 'enlightened' discourse of dual career couples to pro-maternalistic preconceptions that may reflect age or life experiences. For example, the young woman under 30 admired people who could balance work and life, but even slightly older female managers acknowledge gendered family work or a 'maternalist' discourse. 'Women should be able to maintain balance.' 'If a woman has to work she misses out on a lot.' Other women state it more directly. 'It should be both but women feel more responsible.' 'It falls to the mother'.

A discourse of individual, personal choice and the active subject coincides with subjectivities that aspire to 'balance' and address structural constraints in the following response. One female manager reflected the complexities of combining careers and children, saying: A very personal issue - not a general judgement. The couple need to think about those issues before the child arrives. If both parents are in the workforce, they have to have contingencies; day care, relatives, or other alternatives. With the legislation now that you can use your sick leave, it will help. However, there is no easy answer. Not just a female's responsibility ( $F M, 30-34, S, 0)$. This latter quote suggests again that the male responsibility is an 'add on' - while the female responsibility toward her children is taken for granted.

The majority of these responses to questions relating to women's careers and family responsibilities reveal adherence to an enlightened discourse of equal opportunity, a pursuit of an elusive ideal of 'balance' alongside a maternalist discourse in which marriage and a family are considered to be a prime 
responsibility that rests with women. The first and second are most clearly articulated by female managers and the last by male managers. Modifications or elaborations to questions often revealed the operation of an alternative or competing discourse.

\section{Explanations for childlessness}

The following question was posed to tap views relating to women being seen as unreliable in management because of the belief that they will leave to have families. This question therefore invited a response to survey data that indicated that only $14 \%$ of women in the large sample had pre-school dependent children. The question was: "Only 14\% of women managers in the sample had pre-school dependent children. Do you believe that women are remaining childless in order to have a successful management career?" It is noted that the possibility of infertility did not appear in the responses of any of the interviewees.

Three types of responses were received. Firstly, the majority of both male (6) and female (8) responses agreed that women were remaining childless in order to have a successful management career. A male middle manager said: Yes, I would think that with a family and young children AND a career in management, you're always going to have your energies split. That's not a criticism. (MM, 35-39, C, 2). A female middle manager elaborated as follows: Yes, as most women believe their careers are over once they leave work to have a family - many are out of the workplace for several years and may lose skills or not be up to date with new techniques etc. (FM, <30, C, 0). There is recognition here by a young woman that continuity at work is necessary for succes s, but no real engagement with the structural possibility of introducing institutional mechanisms to accommodate or make up for a break in a career. The following views by older, childless women, approaching biological clock issues in terms of their age, clearly draw out the juxtaposition of individual choice and agency discourse with an engagement with societal and structural factors that may constrain this choice. The latter include the long hours work culture and gendered child rearing.

As time goes by it becomes less attractive to me to take a break from my career and have a child. However, I think I could manage a successful career and a child if I changed the parameters of what I do. Perhaps work for myself, for example (FM, 30-34, S, 0), and I think the way society is at the moment, I don't think there's much choice. It's changed in the last 20 years, but if you want a career these days, it's not a 9-5 job anymore. It's very hard to bring up children in that environment, especially if the other partner doesn't have that responsibility ( $F M, 40-44, S, 0)$.

A further observation by an older female manager noted that discrimination on the side of the childless may be occurring to explain the low level of women with young dependent children: It can be a choice in the organization, i.e. "she has no children, so perhaps she can do the job". Self selection seems to occur (FM, 50-55, C, 0). It is of interest to note in this latter comment that in reality, it is management selection, and not 'self-selection', that dictates who will fill certain positions within the organization. 
One male manager framed the cause in terms of general demographic trends: Not necessarily due to a management career. There appears to be a trend to later child bearing in the late 20's and 30's. It's a trend in the last 20 years. (MM, 45-49, C, 0).

Only a small minority constituted the second cluster of responses. One female manager responded 'No' (women were not remaining childless to remain in management). Another female manager stated: "Not so much childless, but maybe husbandless. It's difficult to find a suitable guy. If you like your career, and do want to advance, you don't have the time or energy to put into a partner ( $F M, 40-44, S, 0)$. This response acknowledges inequality in marriage 'work' and pushes causality of childlessness one step further back.

A third type of response from male managers reflected ignorance of and surprise at the gendered pattern of childlessness exposed. For example: I can't really answer that. I don't know. It certainly makes life a lot easier not to have children. (MM, 45-50, C, 0). Most surprising. (MM, 50-54, C, 0).

Most interviewees revealed an awareness of children being an impediment to a woman's career in management. The data from the background quantitative study on numbers of dependent children, and the insight from the interviews reveal that there is no such actual or perceived impediment for men generally.

\section{Conclusion}

Although the sample is small, discourses of 'individual choice', 'enlightened' equality, 'maternalism' and 'elusive balance' often coincide and appear to alter in weight or priority according to the age and sex of the managers. The older females engage more with structural factors and acknowledge gendered realities, and while almost all adhere to the enlightened discourse, women do so more strongly. Maternalistic discourses and ignorance of gendered patterns are more prominent among the males.

This Australian research thus reveals ambivalences, and sometimes complex and competing discursive patterns, as well as surface and deeper attitudes. Critical discourse analysis can in this case be utilized to build a picture of reality beyond blind, surface empiricism. The surface similarity of male and female managers in their attributes and attitudes, noted in the background to this study and by Wajcman and Martin (2002), offers a partial understanding. The context of the work culture is central and worthy of further discussion.

Wajcman (1999) uses terms such as 'loss' and 'sacrifice' to reflect the absence of children among female managers, while others (Hird and Abshoff, 2000; Morell, 1993; Park, 2002; Rowland, 1982a) see 'childfree' women as pioneering a trail that will see the end of hegemonic ideas about the need for a 'true woman' to have children. While not fully reflected in the wary, and sometimes rueful, comments of the women in this study, it could be argued that when projected proportions of childfree or childless women eventuate, the number of women involved would be large enough for workplace 'diversity' to become more entrenched. 
Lorbiecki's (2000) critique of diversity discourse, however, problematizes the notion of difference leading to workplace (and perhaps ultimately social) rewards. Mere presence in certain numbers may be necessary, but not sufficient, to forecast 'equality'. To effectively unravel the meaning of current behaviour and attitudes of women in management requires more in-depth study, such as Boucher's (1997) study based on the memory work of women leaders conducted over nine interview sessions. Although less intense and reflexive on the part of the participants than ideal, the current study offers material for reflection in relation to current feminist debates and hope for some reconciliation between the differing storylines of materialist, "equal opportunity' studies and post structural analyses.

Any 'choice' to be childless for female managers is likely to be generated contextually in a social field in which discourses and symbolic meanings are refracted through material dimensions relating the corporate/corporatized world of often failed family friendly work practices and policies. The increase in childlessness may also reflect acceptance of diversity and a weakening of normative ideals for marriage and motherhood for all women. Just as creative, feminine ways of rethinking women's roles in management and leadership are being imagined and generated, the choice to be childless may indicate and nurture a creative 'social imaginary' about being feminine without motherhood.

For many of these women in management the choice appears, in contrast, to be contextually generated, with recognition that the long hours work culture does not support appropriate parenting. Furthermore, in spite of egalitarian marriage ideals and an enlightened discourse of equality, notions of women's primary duties on the domestic and child-rearing fronts, as part of a maternalist discourse, persist. They reflect the tension between individual and institution and the doubled sense of subject: subject/ed to and subject of action'. They appear to vary around dimensions of age and sex but also coexist within individual women and men. Responses of the women in this study, and in much of the literature, suggest that the proportion of women remaining childless is unlikely to reflect the number leaving teenage years with such an aim. Given the potential scope of childlessness among women in the future, and the continuing task of disentangling the nature of women's subjectivity, theoretical work on gender identity could well consider McNay's exposition of a historically nuanced and dynamic, generative theory of agency, which does not hinge on the mother-child dyad.

Table 1: Demographic profile of interview sample

\begin{tabular}{|cccc|}
\hline & & No. of & No. of \\
\hline & & Males & Females \\
\hline & & & \\
\hline Age & $<30$ & 0 & 2 \\
\hline & $30-34$ & 2 & 3 \\
\hline $35-39$ & 1 & 1 \\
\hline $40-44$ & 3 & 2 \\
\hline
\end{tabular}




\begin{tabular}{|lll|}
\hline \multicolumn{1}{|c|}{$45-49$} & 3 & 0 \\
\hline $50-55$ & 1 & 2 \\
\hline \multicolumn{2}{|c|}{} & \\
\hline Living Arrangements & \\
\hline Couple & 9 & 4 \\
\hline Single & 1 & 5 \\
\hline 'Other' & 0 & 1 \\
\hline \multicolumn{2}{|c|}{} \\
\hline Presence of Dependent & \\
\hline Children & \\
\hline \multicolumn{2}{|c|}{ Yes } & 2 \\
\hline No & 5 \\
\hline No. of sample with \\
\hline pre-school Children \\
\hline
\end{tabular}

Table 2: $\quad$ Legend of interviewees' characteristics

\begin{tabular}{|l|l|}
\hline S & Single including divorced, separated, widowed \\
\hline C & Couple - married or partnership \\
\hline O & $\begin{array}{l}\text { Other - for respondents who did not wish to categorise } \\
\text { themselves as either Single or Couple }\end{array}$ \\
\hline FM & Female Middle manager \\
\hline MM & Male Middle manager \\
\hline
\end{tabular}

\section{INFORMATION ON AUTHORS}

Address for correspondence:

Dr. Glenice J. Wood,

Senior Lecturer in Management,

School of Business,

University of Ballarat,

Victoria, 3353.

Australia.

Email: glen.wood@ballarat.edu.au

Telephone: 0353279425

Fax: 0353279405 
Dr. Glenice Wood is a Senior Lecturer in the School of Business, University of Ballarat, Victoria, Australia.

Dr. Janice Newton is a Senior Lecturer in the School of Behavioural and Social Sciences and Humanities, University of Ballarat, Victoria, Australia.

\section{REFERENCE LIST}

AAP General News (2002) NSW: Electricians walk off job, demanding family friendly hours. October 22, 2002 . Retrieved November 6, 2002, from EBSCOhost.

Adie, J. and Carmody, J. (1991) Families at work: Practical examples from 140 businesses. Melbourne: Council for Equal Opportunity in Employment.

Alexander, B., Rubinstein, R., Goodman, M. and Luborsky, M. (1992) A path not taken: a cultural analysis of regrets and childlessness in the lives of older women. The Gerontologist , 32, 5, 618-626.

Australian Bureau of Statistics (1996) Labour Force Australia. Catalogue No. 6203.0. Canberra: Australian Government Publishing Service.

Australian Bureau of Statistics (2002) Trends in Childlessness, Australian Social Trends. Canberra: Australian Bureau of Statistics.

Australian Women's Year Book (1997) Australian Bureau of Statistics. Catalogue No. 4124.0. Canberra, Australian Government Publishing Service.

Becker, P.E. and Moen, P. (1999) Scaling Back: Dual-Earner Couples' WorkFamily strategies. Journal of Marriage and Family, 61, 4, 1-13.

Boucher, C. (1997) How Women Socially Construct Leadership in Organizations: a Case Study Using memory Work. Gender Work and Organization, 4, 3,149-157.

Brett, J. and Stroh, L. (1999) Women in Management: how far have we come and what needs to be done as we approach 2000? Journal of Management Inquiry, 8, 4, 392-398.

Burton, C. (1991) The promise and the price: The struggle for equal opportunity in women's employment. North Sydney: Allen and Unwin.

Casey, C. (1995) Work, self, and society: after industrialism. London: Routledge.

Cosslett, T., Easton, A. and Summerfield, P. (1996) Women, Power and Resistance: An introduction to Women's Studies. Buckingham: Open University Press. 
Davidson, M. and Cooper, C. (1992) Shattering the Glass Ceiling. The Woman Manager. London: Paul Chapman.

Dempsey, K. (2002) Who gets the best out of marriage: women or men? Journal of Sociology, 38, 2, 91-110.

Family Friendly Work Practices: an information kit for employers (1999) Work and Family Newsletter, Department of Productivity and Labour Relations, Western Australia. 9, 16.

Family Friendly Work Rules: 'Comp time' seen as workplace solution (2002) Foodservice Director, 15, 7, 18.

Franzway, S. (2000) Women Working in a Greedy Institution: Commitment and Emotional Labour in the Union Movement. Gender, Work and Organization, 7, 4, 258-268.

Giddens, A. (1990) The consequences of modernity. Stanford, Calif: Stanford University Press.

Gilding, M. (1997) Australian Families: A Comparative Perspective. Melbourne: Addison Wesley Longman.

Gillespie, R. (2000) When No Means No: Disbelief, Disregard and Deviance as Discourses of Voluntary Childlessness. Women's Studies International Forum, 23, 2, 223-234.

Glezer, H. and Wolcott, I. (1999) Work and Family Life: Reciprocal Effects. Family Matters, 52, 69-74.

Gray, M. and Tudball, J. (2002) Access to Family-friendly Work Practices. Family Matters, 61, 30-35.

Harker, L. (1995) Towards the family friendly employer. In Shaw, J. and Perrons, D. (eds) Making Gender Work: managing equal opportunities. Buckingham: Open University Press.

Heaton, T., Jacobson, C. and Holland, K. (1999) Persistence and Change in Decisions to Remain Childless. Journal of Marriage and Family, 61, 2, 591-540.

Hewlett, S. (2002) Baby Hunger: The New Battle for Motherhood. London: Atlantic Books.

Hird, M. and Abshoff, K. (2000) Women without children: a contradiction in terms? Journal of Comparative Family Studies, 31, 3, 347-366.

Hughes, C. (2002) Key Concepts in Feminist Theory and Research. London: Sage. 
Jenner, L. (1994) Issues and Options for Childless Employees. HR Focus, 71, 3, 22+. Retrieved November 6, 2002 from ProQuest database.

Kesler, C. (1999) The End of the Moral Majority. The Claremont Institute. Available online:

http://www.claremont.org/writings/990401kesler.html Retrieved 16 December 2003.

Lee, C. (2001) CEO as a Recruiter. Executive Excellence, 18, 8, 6-8.

Letherby, G. and Williams, C. (1999) Non-Motherhood: Ambivalent Autobiographies. Feminist Studies, 25, 3, 719-728.

Liff, S. and Ward, K. (2001) Distorted views through the Glass Ceiling: the construction of women's understandings of promotion and senior management positions. Gender, Work and Organization, 8, 1, 19-36.

Lopez, J. (2001) Metaphors of social complexity. In Lopez, J. and Potter, G. (eds) After Postmodernism. London: The Athlone Press.

Lorbiecki, A. (2000) Critical turns in the evolution of diversity management. British Journal of Management, 11, 3, 1-24. Retrieved May 18, 2004, from EBSCOhost.

Manne, A. (2002) And baby makes me. The Age, June1, 1.

McNay, L. (2000) Gender and Agency. Cambridge: Polity.

Meyerson, D.E. and Fletcher, J.K. (2000) A modest manifesto for shattering the Glass Ceiling. Harvard Business Review, 7, 1, 127-136.

Monk, T., Essex, M., Smider, N., Klein, M., Lowe, K., and Kupfer, D. (1996) The impact of the birth of a baby on the time structure and social mix of a couple's daily life and its consequences for well-being. Journal of Applied Social Psychology, 26, 14, 1237-1258.

Morell, C. A. (1993) Intentionally childless women: another view of women's development. Journal of Women and Social Work, 8, 3, 300-316.

Park, K. (2002) Stigma management among the voluntarily childless. Sociological Perspectives, 45, 1, 21-45.

Parker, B. and Fagenson, E.A. (1994) An introductory overview of women in corporate management. In Davidson, M. J. and Burke, R. J. (eds) Women in Management: Current Research Issues. London: Paul Chapman.

Prince, M. (1998) Work culture at heart of work/family programs. Business Insurance, 32, 43, 1-2. Retrieved November 19, 2002, from EBSCOhost. 
Pringle, J. and Tudhope, J. (1996) Family friendly policies: the experiences of three New Zealand companies. Asia Pacific Journal of Human Resources, 34, 3, 77-89.

Pringle, R. (1988) Secretaries Talk: Sexuality, Power and Work. Sydney: Allen and Unwin.

Quinn, D. (2001) Work and the new baby: it's all downhill from here: mothers facing discrimination. The Age News, March 24, 9.

Rowland, R. (1982a) An exploratory study of the childfree lifestyle. The Australian and New Zealand Journal of Sociology, 18, 1, 17-30.

Rowland, R. (1982b) The childfree experience in the aging context: an investigation of the pro-natalist bias of life span developmental literature. Australasian Psychology, 17, 2, 141-150.

Sexton, J. (2002) Day a week overtime - for free. The Australian, December $16,5$.

Shanahan, A. (2002) Follow US example, not the feminists. The Australian, August 13. Retrieved November 21, 2002, from EBSCOhost.

Somers, M. (1993) A comparison of voluntary childfree adults and parents. Journal of Marriage and Family, 55, 643-650.

Still, L.V. (1993) Where to from here? The managerial woman in transition. Sydney: Business and Professional Publishing.

Stratton, L.S. (2003) Gains from trade and specialization: the division of work in married couple households. In Moe, K. S. (ed) Women, Family and Work: Writings on the Economics of Gender. Oxford: Blackwell.

Summers, A. (2003) The End of Equality: Work, Babies and Women's Choices in 21st Century Australia. Milsons Point, N.S.W.: Random House.

Thomson, L. (1998) Flexible working conditions in intractable labour markets? An insight into how female clerical workers balance work and family responsibilities in an era of labour market reform. Paper presented at the 6th Australian Institute of Family Studies Conference, Melbourne, November. Retrieved November 21, 2002 from http://www.aifs.org.

Thornton, A. and Young-DeMarco, L. (2001) Four decades of trends in attitudes towards family issues in the United States: the 1960s through the 1990s. Journal of Marriage and Family, 63, 4, 1-25. Retrieved June 24, 2002, from EBSCOhost. 
Varela, C. (2001) The ethogenics of agency and structure: a metaphysical problem. In Lopez, J. and Potter, G. (eds) After Postmodernism. London: The Athlone Press.

Wajcman, J. (1999) Managing Like a Man: Women and Men in Corporate Management. Cambridge: Polity.

Wajcman, J. and Martin, B. (2002) Narratives of identity in modern management: the corrosion of gender difference? Sociology, 36, 4, 9851002.

Walterscheid, E. (1993) Family-friendly work policies. Women in Business, 45, 6, 30-31.

Whatmore, S., Marsden, T. and Lowe, P. (1994) Gender and Rurality. London: Fulton.

White, N. (2003) Changing conceptions: young people's views of partnering and parenting. Journal of Sociology, 39, 2, 149-164.

Wolcott, I. and Glezer, H. (1995) Impact of the work environment on workers with family responsibilities. Family Matters, 41, 15-19.

Wood, G.J. (2001) Perception: a contributing factor in the different career advancement outcomes of female managers. Unpublished doctoral dissertation, Monash University, Victoria, Melbourne, Australia.

Wood, G.J. and Lindorff, M. (2001) Sex differences in explanations for career progress. Women in Management Review, 16, 4, 152-162.

Wood, G.J. (2003) What does it take to get to the top? Do middle and senior managers agree? Women in Management Review, 18, 3, 122-131.

Zacharias, N. (2002) Balancing work and life: an investigation into the costs and benefits of implementing work-life programs and policies in five Australian companies. Minor Dissertation, MBA, Ballarat, Victoria: School of Business, University of Ballarat.

Zetlin, D. and Whitehouse, G. (1998) Balancing work and family commitments: developments in innovative organizations. Australian Journal of Early Childhood, 23, 3, 9-13. 